\title{
Analisis Perencanaan dan Pengembangan Jaringan Distribusi Air Bersih di PDAM Tulungagung
}

\author{
Firga Yosefa dan Hariwiko Indarjanto \\ Jurusan Teknik Lingkungan, Fakultas Teknik Sipil dan Perencanaan, Institut Teknologi Sepuluh Nopember (ITS) \\ Jl. Arief Rahman Hakim, Surabaya 60111 Indonesia \\ e-mail: hwcorp@yahoo.com
}

\begin{abstract}
Abstrak-PDAM Tulungagung merupakan instansi yang bertanggungjawab dalam pengelolaan air bersih di Kabupaten Tulungagung. Pengelolaan air bersih di PDAM Tulungagung unit BNA Tulungagung dibagi dalam 6 kecamatan dan 1 kecamatan rencana pengembangan yang terdiri dari Kecamatan Tulungagung, Kecamatan Boyolangu, Kecamatan Gondang, Kecamatan Karangrejo, Kecamatan Kauman, Kecamatan Sumbergempol dan rencana wilayah pengembangan yaitu Kecamatan Ngantru. Dari 7 kecamatan tersebut, sistem jaringan distribusi air bersih belum merata ke pelanggan dan tingkat kebocoran air yang cukup tinggi. Untuk mengatasi kendala-kendala tersebut, maka perlu dilakukan analisis dan perencanaan terhadap sistem jaringan distribusi air bersih. Periode perencanaan 10 tahun dilakukan untuk tahun 2017-2026 dengan menghitung proyeksi jumlah penduduk dan fasilitas umum untuk mengetahui kebutuhan air. Sistem penyediaan air bersih di 6 kecamatan eksisting didistribusikan dari sumber air permukaan yaitu Kali Song dengan kapasitas produksi 150 liter/detik. Kapasitas digunakan juga dalam rencana pengembangan di Kecamatan Ngantru. Dalam sistem ini, akan direncanakan model sistem jaringan pipa distribusi menggunakan program Epanet 2.0, kemudian dikontrol menggunakan meter induk. Dengan adanya alternatif sistem jaringan ini dapat mengontrol tingkat kebocoran air dan dapat memenuhi cakupan wilayah pelayanan.
\end{abstract}

Kata kunci-air bersih, distribusi, epanet, perencanaan, Tulungagung.

\section{PENDAHULUAN}

$\mathrm{U}$ NTUK memenuhi kebutuhan air bersih di PDAM BNA Tulungagung diperlukan sistem pelayanan air bersih yang baik agar persediaan air tetap terjaga sehingga dapat dikonsumsi oleh masyarakat secara aman dari aspek kualitas, kuantitas, dan kontinuitas. Kabupaten Tulungagung mempunyai luas wilayah $1.055,65 \mathrm{~km}^{2}$ dan jumlah penduduk 1.053.276 jiwa dengan pertumbuhan penduduk sebanyak $1,53 \%$ per tahun [1]. PDAM BNA Tulungagung melayani 6 kecamatan yaitu kecamatan Tulungagung, Karangrejo, Sumbergempol, Kauman, Gondang, dan Boyolangu serta terdapat rencana pengembangan di 1 kecamatan yaitu kecamatan Ngantru. Tingkat Pelayanan air bersih sebanyak 11.140 sambungan rumah, debit rata-rata 100 Liter/orang.hari, jumlah kapasitas pengolahan air minum (2 unit) 200 Liter/detik, serta kapasitas produksi 150 Liter/detik. Proporsi air yang disuplai menggunakan continuos system sebesar 91,67\%.

Berdasarkan data di atas permasalahan secara umum yang terjadi di PDAM BNA Tulungagung adalah pelayanan $\pm 64,29 \%$ namun tingkat kebocoran air yang cukup tinggi yaitu $\pm 24,5 \%$. Dilihat dari kondisi eksisting perpipaan yang ada, sistem perpipaan banyak mengalami masalah, seperti korosi pada pipa dan kebocoran pada pipa yang disebabkan faktor umur pipa sehingga kualitas air bersih menjadi buruk.

Dari uraian permasalahan yang terjadi di atas di 6 kecamatan yang dilayani PDAM BNA Tulungagung dan 1 kecamatan rencana pengembangan, maka direncanakan akan dibuat periode perencanaan selama 10 tahun ke depan, dengan target meningkatkan pelayanan air bersih serta merencanakan pengembangan jaringan baru di kecamatan Ngantru dikarenakan debit sumur masing-masing warga kecil sehingga mempengaruhi dalam memenuhi kebutuhan air bersih, oleh karena itu diperlukan pelayanan dari PDAM BNA Tulungagung.

\section{GAMBARAN UMUM WILAYAH PERENCANAAN}

Pengelolaan air bersih 6 kecamatan yang dikelola oleh PDAM BNA Tulungagung terdiri dari kecamatan Tulungagung, Karangrejo, Sumbergempol, Kauman, Gondang, dan Boyolangu. Serta ada 1 rencana wilayah pengembangan baru di Kecamatan Ngantru. Sumber air berasal dari air permukaan yaitu Kali Song dengan kapasitas produksi 150 liter/detik dengan kapasitas reservoir $2.500 \mathrm{~m}^{3}$ serta kebutuhan air rata-rata 100 liter/orang.hari. Wilayah perencanaan dan pengembangan jaringan distribusi air bersih dapat dilihat pada Gambar 1.

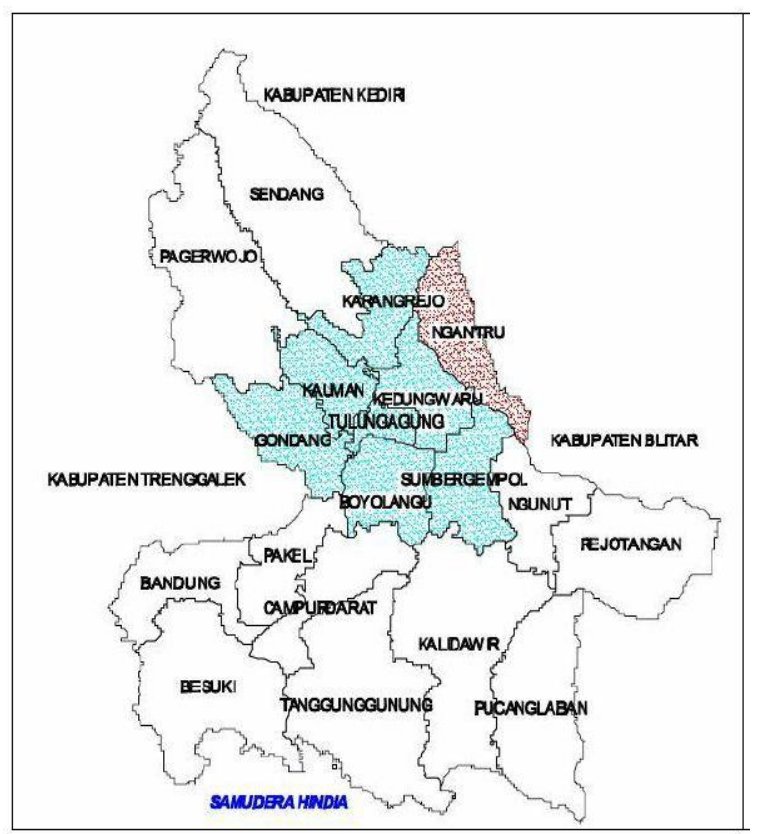

Gambar 1. Wilayah Perencanaan dan Pengembangan 


\section{METODE}

Metode yang digunakan dalam perencanaan ini ialah sebagai berikut:

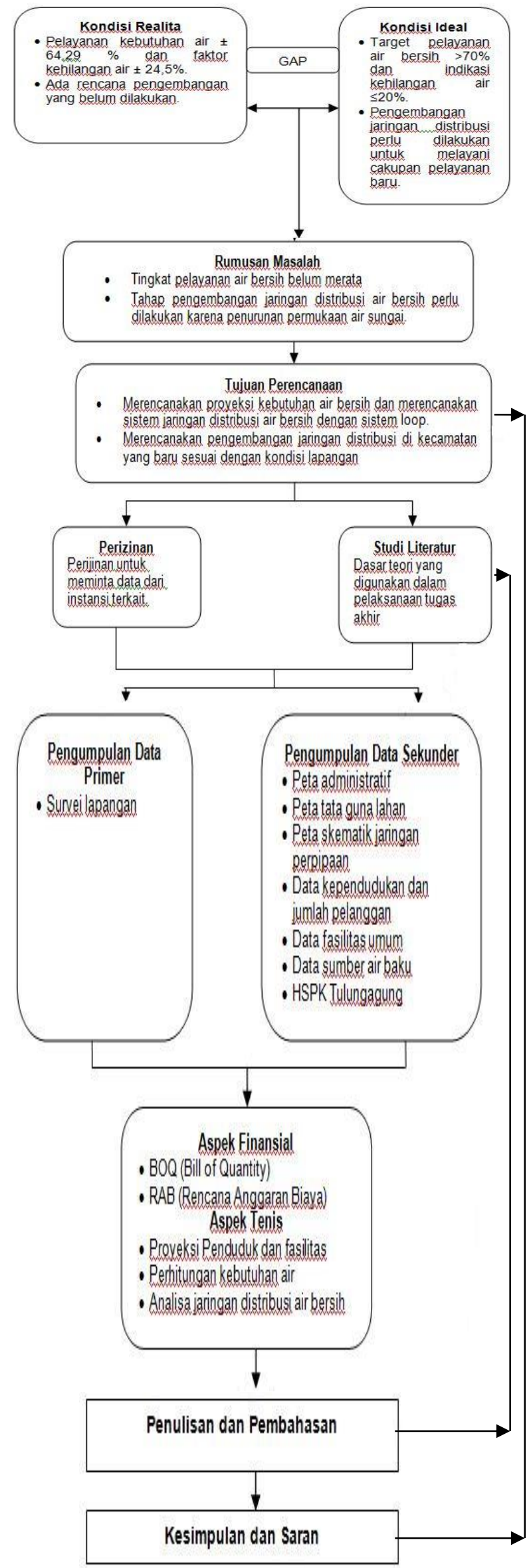

Gambar 2. Diagram alur metode perencanaan

\section{ANALISA DATA DAN PEMBAHASAN}

\section{A. Analisa Kondisi Eksisting Jaringan Perpipaan}

Analisa kondisi eksisting jaringan perpipaan ini menggunakan program Epanet 2.0. Hasil analisa akan menjadi acuan dalam perbaikan sistem jaringan distribusi di 6 kecamatan dan 1 kecamatan rencana pengembangan baru. Data-data yang diperlukan dalam menganalisa kondisi eksisting adalah data skematik jaringan perpipaan dari instansi yang terkait.

Sumber air baku dari Kali Song dengan debit 750 liter/detik masuk melalui intake, selanjutnya air tersebut diolah melalui IPA, kemudian dari IPA air dialirkan lewat pipa untuk ditampung di ground reservoir dengan kapasitas $2.500 \mathrm{~m}^{3}$ dengan elevasi $+225 \mathrm{~m}$. Dari ground reservoir tersebut lalu air dialirkan menuju BPT (Bak Pelepas Tekan) yang terletak pada elevasi $+167 \mathrm{~m}$. Selanjutnya dari BPT, air didistribusikan ke 6 kecamatan yang dilayani oleh PDAM BNA Tulungagung yaitu Kecamatan Tulungagung, Boyolangu, Karangrejo, Kauman, Gondang, dan Sumbergempol. Di dalam proses pendistribusian tersebut air dialirkan sementara melalui bangunan menara air yang terdapat di kecamatan kota Tulungagung. Selanjutnya dari bangunan menara air tersebut, air didistribusikan ke 6 kecamatan. Sistem perpipaan yang digunakan untuk transmisi dan distribusi ada bermacam-macam yaitu pipa baja, PVC, dan ACP. Sistem distribusi menggunakan sistem gravitasi. Berikut merupakan gambar kondisi eksisting jaringan perpipaan dapat dilihat di Gambar 3.

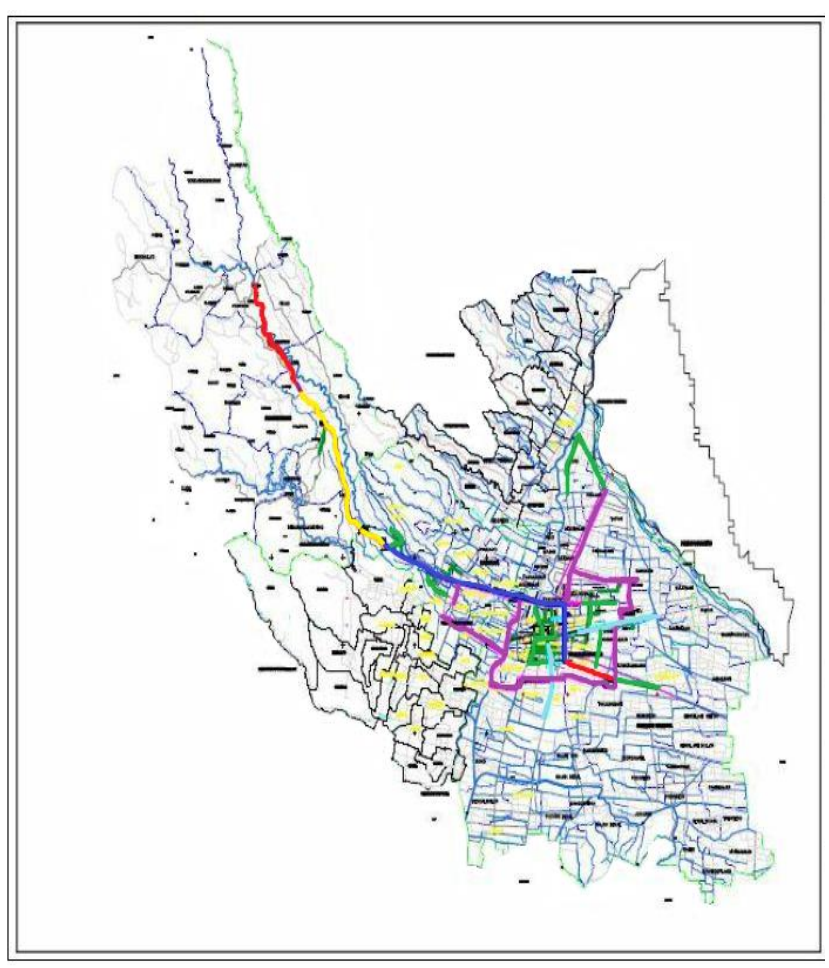

Gambar 3. Kondisi Eksisting Jaringan Perpipaan

Data-data yang diinput dalam program Epanet 2.0 adalah peta jalur pipa, elevasi tiap node, panjang pipa, diameter pipa, koefisien kekasaran pipa. Setelah semua yang dibutuhkan sudah didapat dan sudah diinput ke dalam program Epanet 2.0, maka analisa hidrolik sudah dapat dilakukan. Analisa jaringan perpipaan meliputi pressure (sisa tekan), kecepatan aliran, dan unit headloss jaringan perpipaan.

Berdasarkan analisa hidrolik pada Epanet 2.0 dari kondisi eksisting perpipaan adalah: 
Analisa kondisi pressure menunjukkan bahwa pressure cukup memenuhi untuk pelayanan. Kecepatan aliran sesuai standar yaitu 0,3-2 m/detik, hasil analisa epanet di atas tadi menunjukkan masih ada kecepatan di bawah batas nilai yang ditetapkan yaitu di bawah $0,3 \mathrm{~m} /$ detik. Unit headloss 10 $\mathrm{m} / \mathrm{km}$, namun unit headloss tersebut bisa lebih besar tergantung kondisi lapangan [2].Hasil jaringan Epanet 2.0 dapat dilihat pada Gambar 4 dan Gambar 5.

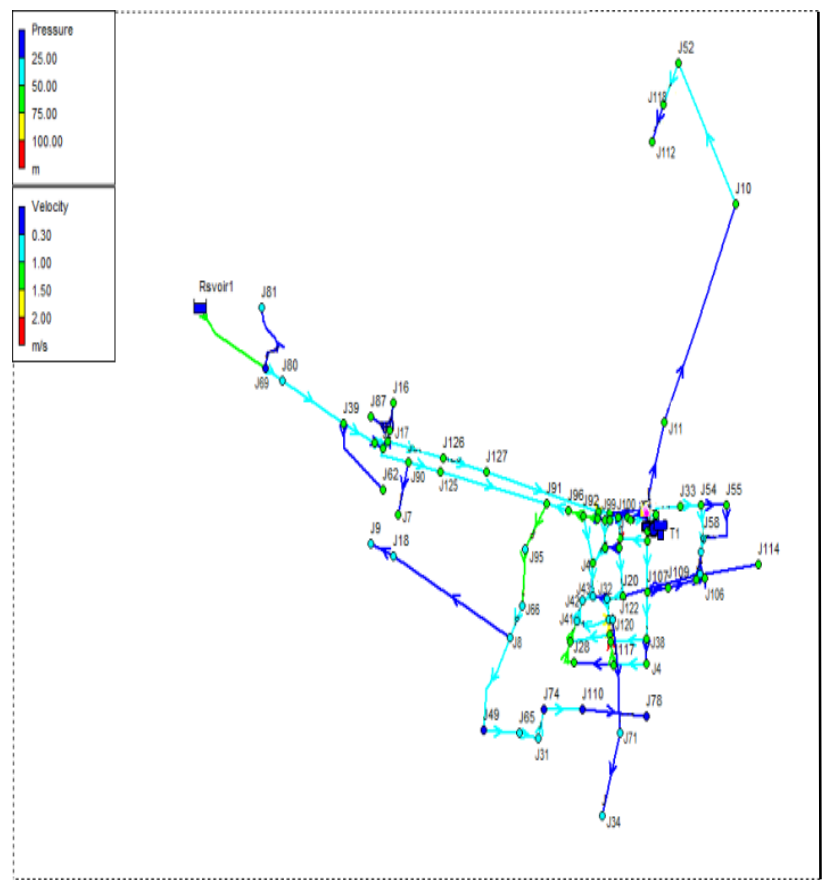

Gambar 4. Hasil Analisa Kondisi Eksisting (Pressure dan Velocity)

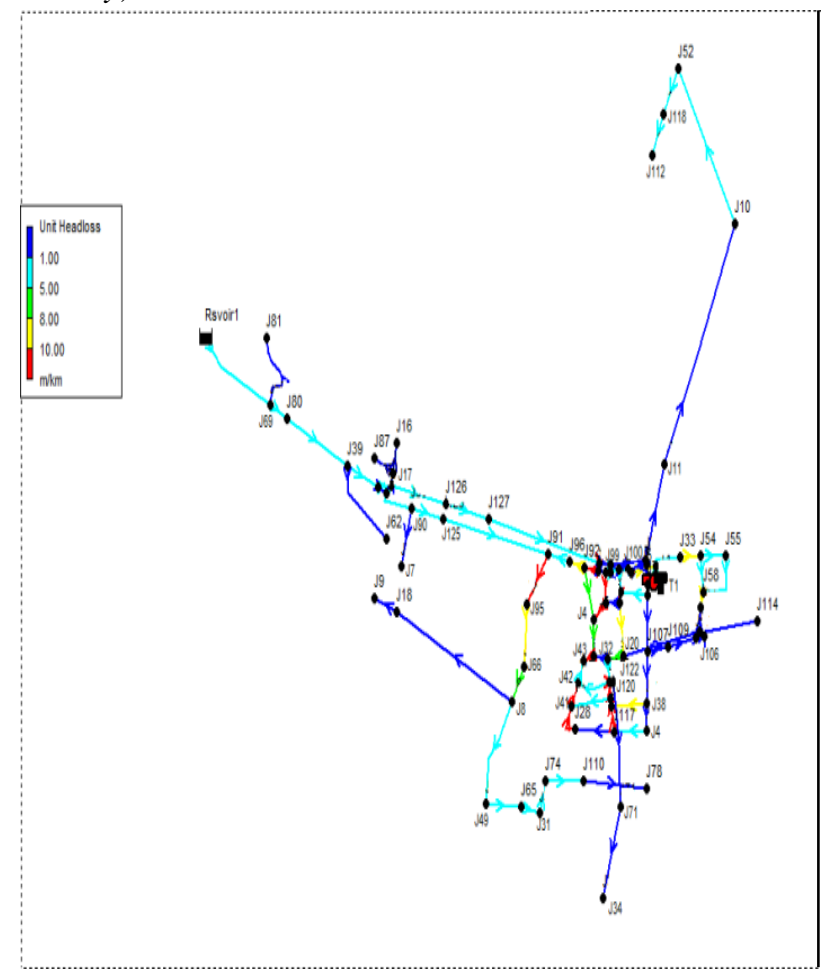

Gambar 5. Hasil Analisa Kondisi Eksisting (Unit Headloss)

Berdasarkan hasil analisa hidrolik dengan epanet, bahwa perlu adanya perbaikan jaringan perpipaan dengan memparalel perpipaan yang belum memenuhi standar serta membuat sistem loop agar dapat mengontrol kebocoran air yang ada agar dapat memberikan pelayanan distribusi air bersih yang cukup ke setiap daerah pelayanan [3].

\section{B.Perencanaan Jaringan Distribusi Air Bersih \\ 1. Proyeksi Penduduk}

Perencanaan jaringan distribusi air bersih direncanakan 10 tahun ke depan yaitu dari tahun 2017 - 2026. Daerah perencanaan yang diproyeksikan yaitu 6 kecamatan dan 1 rencana pengembangan. Jumlah penduduk dapat dilihat pada Tabel 1.

Tabel 1.

Jumlah Penduduk

\begin{tabular}{lllll}
\hline \hline \multirow{2}{*}{ No. } & \multirow{2}{*}{ Kecamatan } & 2.005 & 2.010 & 2.014 \\
\hline 1 & Tulungagung & 66.185 & 68.561 & 65.915 \\
2 & Boyolangu & 73.868 & 74.260 & 80.099 \\
3 & Gondang & 54.829 & 55.731 & 54.493 \\
4 & Karangrejo & 38.549 & 39.740 & 39.524 \\
5 & Kauman & 50.325 & 51.561 & 49.688 \\
6 & Sumbergempol & 62.864 & 65.066 & 65.822 \\
7 & Ngantru & 49.515 & 54.640 & 54.323 \\
\hline \hline
\end{tabular}

Perhitungan proyeksi penduduk terdapat tiga metode yang digunakan yaitu metode aritmatik, geometrik, dan least square. Dari ketiga metode tersebut kemudian dicari koefisien korelasinya untuk mencari metode yang akan digunakan dalam menghitung proyeksi penduduk.[4] Dari hasil perhitungan nilai korelasi pada setiap metode di atas, metode geometrik yang akan digunakan dalam perhitungan proyeksi penduduk karena nilai koefisien korelasinya mendekati 1. Proyeksi penduduk dapat dilihat pada Tabel 2

Tabel 2.

Proyeksi Penduduk

\begin{tabular}{cllll}
\hline \hline NO & KECAMATAN & $\mathbf{2 . 0 1 5}$ & $\mathbf{2 . 0 2 0}$ & $\mathbf{2 . 0 2 6}$ \\
\hline 1 & Tulungagung & 66.167 & 67.405 & 68.921 \\
2 & Boyolangu & 80.406 & 81.908 & 83.752 \\
3 & Gondang & 54.706 & 55.729 & 56.983 \\
4 & Karangrejo & 39.677 & 40.421 & 41.331 \\
5 & Kauman & 49.880 & 50.810 & 51.955 \\
6 & Sumbergempol & 66.706 & 67.315 & 68.823 \\
7 & Ngantru & 54.531 & 55.554 & 56.803 \\
\hline \hline
\end{tabular}

\section{Kebutuhan air}

Kapasitas produksi saat ini adalah 150 liter/detik. Kebutuhan rata-rata 100 liter/orang.hari dengan persentase pelayanan $64,29 \%$. Sedangkan untuk kebutuhan air minimal dan maksimal di 6 kecamatan yang dilayani PDAM BNA Tulungagung adalah 82,05 liter/orang.hari dan 110 liter/orang.hari. Untuk pemakaian kebutuhan air pada jam puncak adalah sebesar 150 liter/orang.hari.

Kebutuhan air yang direncanakan 10 tahun yaitu mulai 2017-2026 dengan target persen pelayanan $>70 \%$. Hasil perhitungan kebutuhan air tahun 2017 sebesar 110,81 liter/detik, selanjutnya pada 5 tahun pertama kebutuhan air penduduk mencapai 116,45 liter/detik. Dan pada tahun 2026 kapasitas produksi masih mampu untuk melayani kebutuhan air penduduk yaitu sebesar 142,77 liter/detik dari total kapasitas produksi 150 liter/detik. 


\section{Pembuatan sistem loop dan perombakan jaringan perpipaan}

Seperti yang telah dijelaskan di pembahasan sebelumnya, bahwa sistem jaringan kondisi eksisting digunakan sebagai patokan dalam merencanakan sistem jaringan distribusi air bersih. Hasil kondisi eksisting di atas tadi menunjukkan bahwa dari informasi kondisi eksisting yang didapat adalah sistem jaringan perpipaan yang masih belum dibuat loop, velocity yang masih kurang yaitu $<0,3$ $\mathrm{m} / \mathrm{s}$, dan unit headloss yang masih tinggi yaitu $>10 \mathrm{~m} / \mathrm{km}$ sehingga menyebabkan kecepatan aliran menjadi kecil.

Oleh karena itu diperlukan beberapa solusi alternatif untuk mengatasi permasalahan perpipaan di atas yaitu dengan cara memparalelkan pipa, memperkecil atau memperbesar diameter pipa berdasarkan kondisi lapangan yang ada, serta membuat sistem loop di beberapa kecamatan agar memudahkan mengontrol kehilangan air. Untuk rencana pengembangan di kecamatan baru yang akan dilayani, perpipaan dari kondisi eksisting akan langsung disambungkan ke kecamatan yang baru untuk memenuhi daerah pelayanan yang baru sesuai kondisi lapangan.

Perencanaan jaringan distribusi ini akan dibuat sistem loop dengan jumlah loop sebanyak 6 loop dan kemudian direncanakan dipasang meter induk pada masing-masing loop sesuai jumlah pelayanan SR yaitu 500-2.000 SR.[5] Sedangkan untuk permasalahan jaringan perpipaan seperti unit headloss yang masih tinggi dan kecepatan aliran yang belum memenuhi standar, maka akan dilakukan paralel pipa berdasarkan kondisi lapangan yang ada. Kriteria di dalam penetapan standar untuk menganalisa sistem jaringan perpipaan adalah pressure 10-70 $\mathrm{m}$, kecepatan aliran 0,3-2 $\mathrm{m} /$ detik, dan unit headloss $10 \mathrm{~m} / \mathrm{km}$. Berikut merupakan hasil evaluasi jaringan perpipaan dapat dilihat pada Gambar 6 dan Gambar 7.

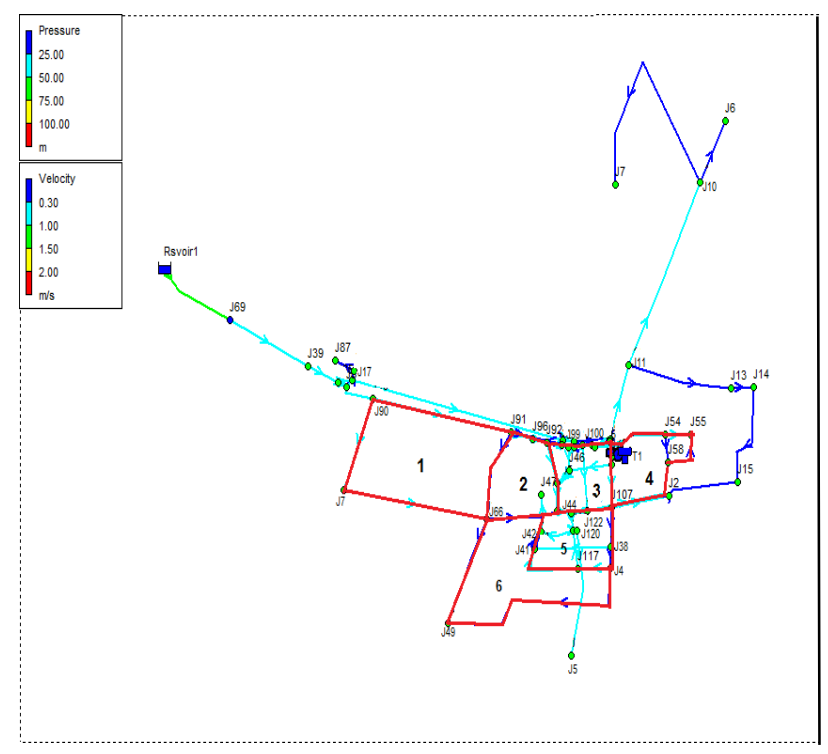

Gambar 6. Hasil Evaluasi Jaringan Perpipaan (Pressure dan Velocity)

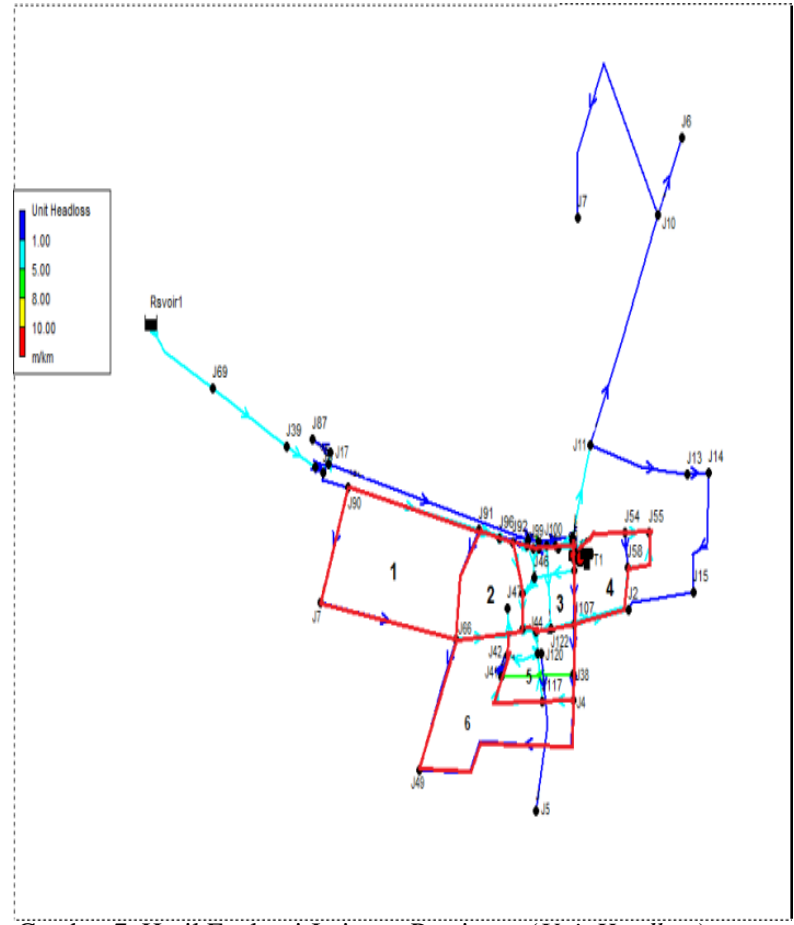

Gambar 7. Hasil Evaluasi Jaringan Perpipaan (Unit Headloss)

Dari gambar di atas menunjukkan bahwa pressure sudah memenuhi batas nilai yang dianjurkan. Kecepatan aliran sebesar 0,3-1,06 m/detik, serta unit headloss di perpipaan 10 $\mathrm{m} / \mathrm{km}$, namun unit headloss bisa lebih besar tergantung kondisi lapangan.

\section{Pengembangan Jaringan Distribusi}

Di dalam mengembangkan jaringan distribusi ada beberapa faktor yang mempengaruhi dilakukannya pengembangan, hal tersebut agar pengembangan jaringan distribusi dapat dilakukan sesuai perencanaan. Salah satunya adalah keadaan topografi daerah yaitu debit air sungai yang makin mengecil sehingga mempengaruhi debit sumur warga dalam memenuhi kebutuhan air bersih pada saat musim kemarau sehingga diperlukan pelayanan air bersih di daerah tersebut [6]. Selain memperhitungakan faktor di atas juga perlu memperhitungkan pressure (sisa tekan), kecepatan aliran, serta debit air apakah masih mencukupi atau tidak jika dilakukan pengembangan.

Pada rencana pengembangan ini akan dilakukan di Kecamatan Ngantru di Kelurahan Ngantru dan Kelurahan Bendosari. Untuk rencana pengembangan tersebut akan dilakukan pemasangan 60 SR. Hal ini merupakan jumlah minimal pemasangan SR sesuai pelayanan PDAM BNA Tulungagung. Untuk rencana pengembangan tersebut di Kecamatan Ngantru ada 60 SR sedangkan di Kecamatan Sumbergempol ada 60 SR. Jumlah SR tersebut merupakan jumlah minimal pemasangan SR sesuai pelayanan PDAM Tulungagung.

Untuk masing-masing SR yang dipasang tersebut berada di Kecamatan Ngantru Kelurahan Ngantru 30 SR, Kelurahan Bendosari 30 SR serta Kecamatan Sumbergempol Kelurahan Jabalsari 30 SR, Kelurahan Sambirobyong 30 SR. Berikut merupakan hasil rencana pengembangan dapat dilihat pada Gambar 8 dan Gambar 9. 


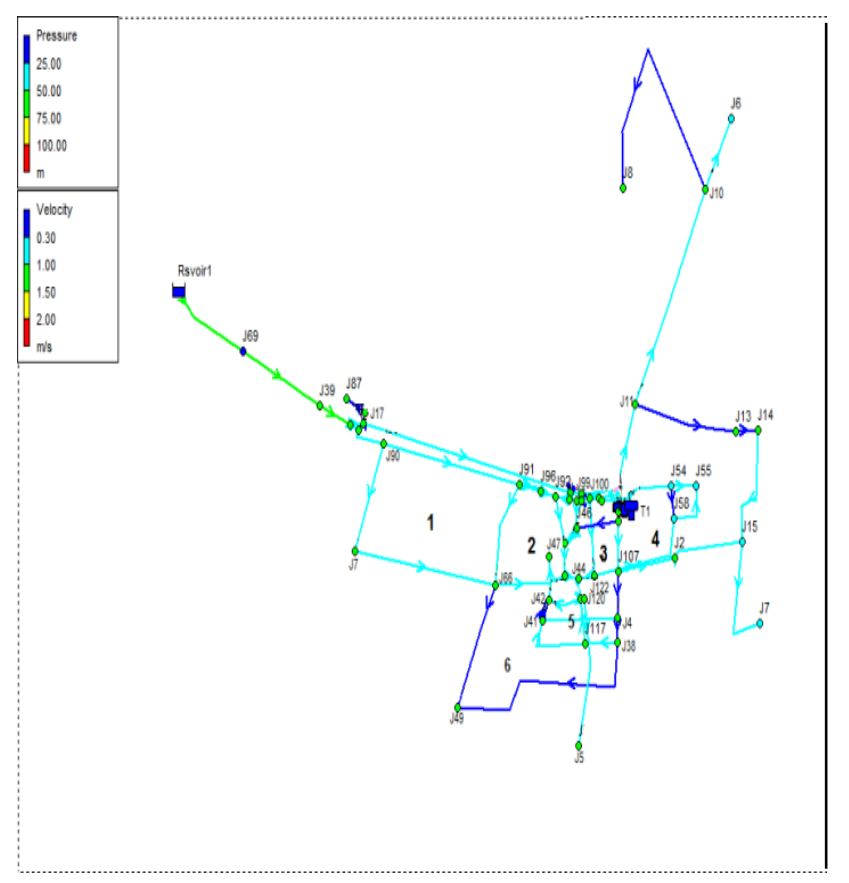

Gambar 8. Hasil Rencana Pengembangan (Pressure dan Velocity)

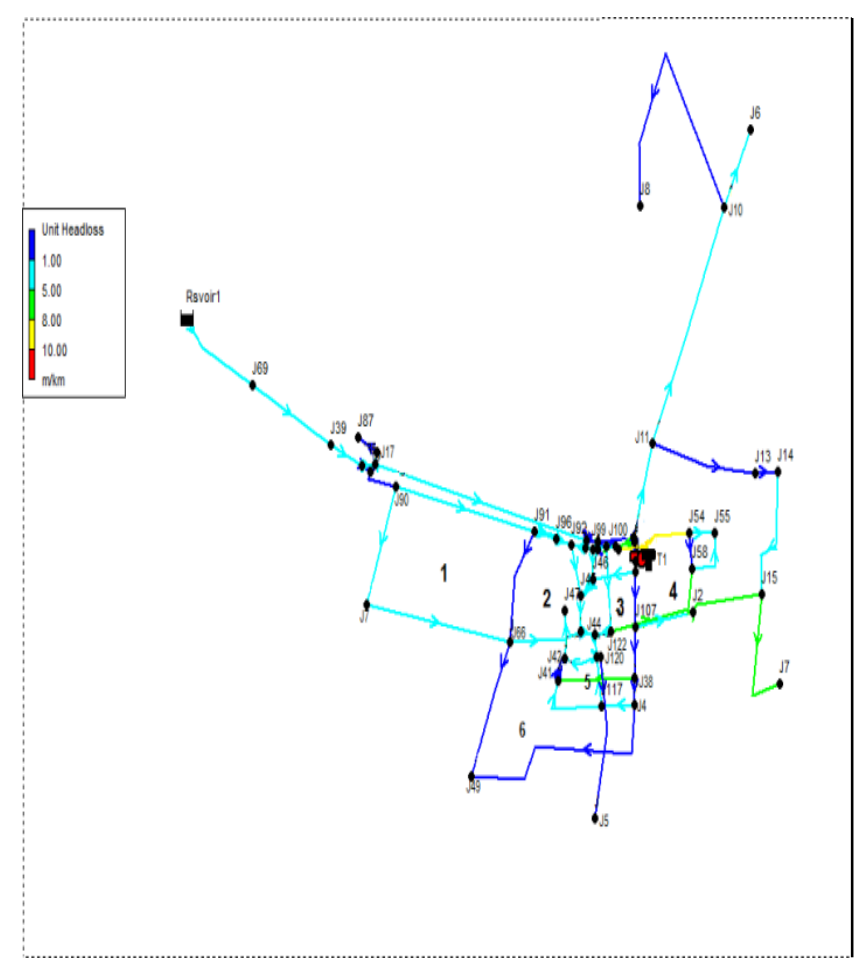

Gambar 9. Hasil Rencana Pengembangan (Unit Headloss)

Dari gambar di atas menunjukkan bahwa nilai pressure (sisa tekan) masih dapat mencukupi untuk dilakukan rencana pengembangan dengan sisa tekan 13,66 m pada titik terjauh rencana pengembangan di Kecamatan Ngantru. Kecepatan aliran $0,75 \mathrm{~m} /$ detik. Sedangkan untuk unit headloss pada pipa baru pengembangan di bawah $10 \mathrm{~m} / \mathrm{km}$.

\section{Bangunan Pelengkap}

Di dalam merencanakan jaringan distribusi air bersih diperlukan beberapa bangunan pelengkap dalam membangun jaringan perpipaan. Bangunan pelengkap ini adalah thrust block, thrust block ini berfungsi untuk menahan beban hidrolik air pada setiap belokan perpipaan, terutama pada pipa yang diparalel. Thrust block yang digunakan ini adalah bend $90^{\circ}$ dengan jumlah thrust block 16 buah.

\section{Rekapitulasi Rencana Anggaran Biaya}

Tabel 3.

Rekapitulasi Rencana Anggaran Biaya

\begin{tabular}{llr}
\hline \hline No. & Uraian Kegiatan & Harga (Rp) \\
\hline 1 & Pengadaan Pipa & 42.830 .500 \\
2 & Pengadaan Aksesoris & 253.000 .600 \\
3 & Penanaman Pipa & 163.451 .000 \\
4 & Pembetonan Thrust Block $90^{\circ}$ & 1.595 .000 \\
& & Total \\
\hline \hline
\end{tabular}

\section{KESIMPULAN}

a. Sistem jaringan distribusi air bersih menggunakan sistem pengaliran secara gravitasi. Pipa-pipa eksisting yang tidak memenuhi standar akan dilakukan rencana perombakan yaitu pipa dibuat paralel dan pembuatan sistem loop dengan terdiri dari 6 loop dan masing-masing loop ada 2 tapping, sehingga total ada 12 tapping di dalam suatu sistem jaringan perpipaan. Hasil running epanet dan pembentukan sistem loop menunjukkan bahwa pipa dapat memenuhi standar dalam hal kecepatan aliran, tekanan, dan unit headloss.

b. Pelayanan kebutuhan air bersih dapat dilayani sampai $89,37 \%$ pada tahun 2026. Kapasitas produksi yang digunakan adalah 150 Liter/detik. Kapasitas produksi tersebut digunakan untuk melayani 6 kecamatan di PDAM BNA Tulungagung dan selanjutnya digunakan untuk rencana pengembangan di Kecamatan Ngantru. Dan sampai tahun 2026 kapasitas produksi tersebut masih cukup untuk melayani kebutuhan air penduduk yaitu sebesar 142,77 Liter/detik.

c. Anggaran biaya yang dibutuhkan dalam perencanaan ini adalah sebesar Rp 460.877.100

\section{DAFTAR PUSTAKA}

[1] BPS Kabupaten Tulungagung 2005-2014. 2014. Pemerintah Kabupaten Tulungagung.

[2] Husian, S.K. 2006. A Textbook of Water Supply. London. Oxford \& IBH

[3] Departemen PU Direktorat Jendral Cipta Karya. 2003. "Petunjuk Teknis Pelaksanaan SPAM Pemukiman dan Prasarana Wilayah", Jakarta.

[4] Mangkoedihardjo, S dan Samudro, G. 2012. "Evaluasi dan Perencanaan Kebutuhan Air". Guna Widya. Surabaya

[5] Klaas K. S. Y. D. 2009. Design Jaringan Pipa. Mandar Maju. Bandung

[6] Departemen PU Direktorat Jendral Cipta Karya. 2000. "Petunjuk Teknis Pelaksanaan Pengembangan SPAM Sederhana", Jakarta. 